\title{
Teaching Anatomy and Physiology to Engineers in THE Biomedical EngineERING Program
}

\author{
Zahra Moussavi and Brian Lithgow \\ Department of Electrical \& Computer Engineering \\ University of Manitoba, Winnipeg, MB Canada
}

\begin{abstract}
The merger of natural sciences with engineering and creation of biomedical engineering (BME) has brought innovation to the practice of medicine that could only be dreamed about a decade ago. By many accounts, we are now at the outset of Biomedical Century, and the need for engineers, natural scientists and physicians trained in biomedicine is greater than ever. While several universities in US and Canada have started BME program at the undergraduate level, many universities, particularly in Canada, have the BME program at graduate level with some BME related courses at undergraduate level. Therefore, we must be able to teach the fundamentals of human anatomy and physiology to students with engineering background, whom may have no background in biology.
\end{abstract}

While a simple solution might be to refer students to take anatomy courses in the faculty of medicine, the author of this paper believes these courses would be much more efficient if they are taught by an engineer trained in medicine. There are three main approaches in engineering design: top-down and bottom-up and a blend of the two approaches [1-3]. There are many debates as which approach is most efficient in a particular area of science and philosophy. we believe engineers often use top-bottom approach for learning new concepts; through their main discipline, engineers, in general, learn the problem solving skills, in which they try to break a complex problem into several smaller problems and narrow down logically by cause and effect analysis; in another word they follow a top-down approach. Being trained with this approach, therefore, they may feel lost in a basic anatomy or physiology course as they often have a bottom-up approach in teaching the materials. This paper discusses the top-down approach in teaching anatomy and physiology to engineering students, and offers some insights for teaching BME courses.

\section{References}

[1] Ullman D.G. "Issues critical to the development of design history, design rationale and design intent systems," in Proc. 6th International Conference on Design Theory and Methodology, 1994 ASME Design Technical Conferences, 1994, DE v 68, pp. 249-258.

[2] Paz-Soldan J.P. and Rinderle J.R., "The alternate use of abstraction and refinement in conceptual mechanical design," in Proc. ASME Winter Annual Meeting, ASME, Dec. 1989.

[3] Terpenny J.P., Nnaji B. O. and Bohn J.H., "Blending top-down and bottom-up approaches in conceptual design," in Proc. 7th Ann. Indus. Eng. Research Conf., May 1998. 